\title{
Design of ATM Accessing System for Blind using Real-Time Video Processing through Gestures
}

\author{
Shruthi.G ${ }^{1}$, Sarayu.K.P $P^{1}$ \\ Sangeetha. $R^{1}$, Sanjoy Das ${ }^{2}$ \\ ${ }^{1}$ 8th semester, Dept of Computer Science, KSIT, Bangalore \\ ${ }^{2}$ Asst Professor, Dept of Computer Science, KSIT, Bangalore
}

\begin{abstract}
About 285 million people are visually impaired worldwide: 39 million are blind and 246 million have low vision (severe or moderate visual impairment) preventable cause are as high as $80 \%$ of the total global visual impairment burden. Globally, uncorrected refractive errors are the main cause of visual impairment. Cataracts are the leading cause of blindness $65 \%$ of visually impaired, and $82 \%$ of blind people are over 50 years of age, although this age group comprises only $20 \%$ of the world population[1].Blindness can be classified into 3 types, Complete blindness, Night blindness, Color blindness. The main problems faced by blind people: during financial transactions especially in ATMs. In the existing ATMs, Braille is inscribed on the keypad to facilitate blind. But, What if the people doesn't know Braille, how to insert a card? The friend accompanying him might get to know the password or someone else can come to know of his pin number. A stranger might try to help the blind win the trust and rob him. So, we propose to design and develop a safer and secure ATM accessing system for the blind.
\end{abstract}

\section{General Terms}

Image Processing, Security, Gesture Recognition, Java

\section{Keywords}

ATM Machines, Hand Gesture Recognition, Blind, Image Processing

\section{INTRODUCTION}

About 285 million people around the world are visually impaired and about 35 million are blind. There are 3 kinds of blindness-night blindness, complete blindness, and Color blindness. One of the problems they face in their routine is during ATM transactions. Though ATMs are inscribed with Braille it does not completely eliminate the problems faced by blind people [1].

The various reasons for the failure are-What if the blind person using the system does not know Braille and does not know how to use it, the blind person is most of the time accompanied by someone who helps him in his transactions, that person may accidently or purposely see the authentication details of the blind person and may misuse the same for his own use. Since blind person cannot see he may be watched by a robber and may rob the blind person. The blind person also cannot be confirmed about the correctness of the money he opted and the amount he received [7].

Existing solution, Talking ATM is an automated teller machine that provides audible instructions to a person who cannot read an ATM screen to help him to independently use the machine. All audible information is delivered privately through a standard headphone jack on the machine or a separately attached telephone headset. Information is delivered to the customer either through pre-recorded sound files or via text-to-speech synthesis. A user plugs a standard headset into the jack and can hear instructions such as "press 1 for withdrawal", "press 2 for deposit". There is an audible orientation for first time users and audible information describing the location of features such as number keypad, deposit slot and card slot [2].

\section{LITERATURE SURVEY}

Magic Glove aims to bridge the gap between the user and traditional physical hardware devices. Given the high learning curve in understanding how to use foreign technologies, it hopes to break away from conventional control mechanisms and explore an intuitive way to control these devices. Magic Glove provides a tangible interface that relies on hand gestures to wirelessly control any device or software. By removing the distance between the user and traditional hardware devices, the goal of Magic Glove is to make the feel more like an extension of the body as opposed to an external machine.

Simple hand gestures are captured from the Magic Glove and this input is used to wirelessly control a modified RC car. Controlled variables include speed, steering, lights and sounds using a combination of flex, force and gyroscopic sensors. Multiple variables are controlled simultaneously as Magic Glove outputs a constant control signal [3].

Though Magic Glove has many advantages and scope in many fields it does have many disadvantages too. The sensors used in the Glove should be of high precision else if low precision sensors are used the system may fail to capture the gestures appropriately. Since sensors are a part of the system it is not very cost effective. The Glove is embedded with many sensors and wires which make the whole system very bulky and difficult to carry around. The system along with controllers, cables and sensors is very complex and not very easy to understand by common man [4].

\section{METHODOLLGY}

\subsection{System Level Flowchart}

The gist of the complete work is as shown in Fig 1. As per any Image Processing work, the video is captured from the webcam which is connected to the system. Processes like segmentation, noise removal and gesture identification is done here. 


\subsection{Hardware and Software Requirements}

A webcam with resolution $5 \mathrm{mp}$ is used to capture gestures of better quality which is connected to a desktop/laptop which has operating system Windows XP and above, processor core i3 and above. Headset is used to acknowledge the person. Our project is carried out using java language version being 1.7 or above and editor being eclipse.

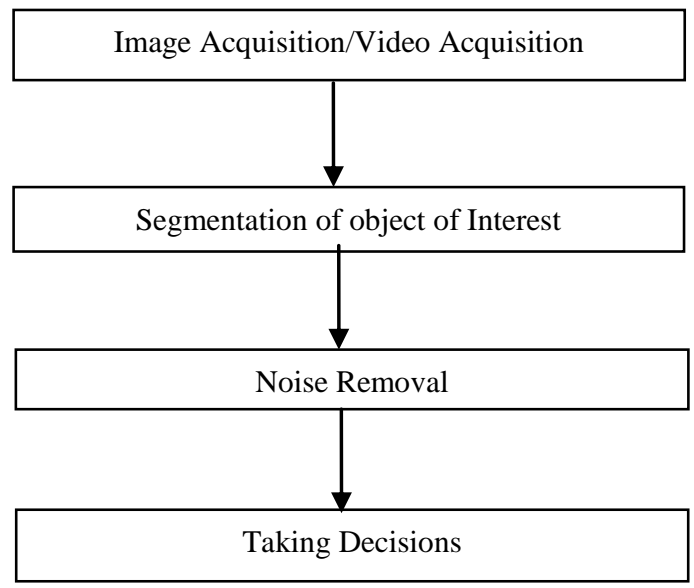

Fig 1

\section{Design and Implementation}

\subsection{Setup Design}

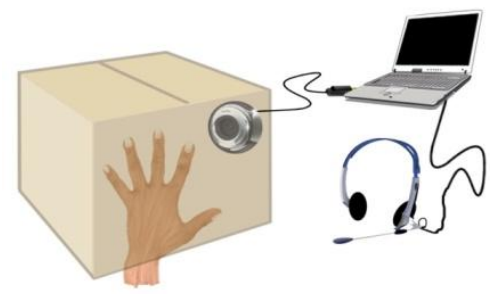

Fig 2: Architecture of the Proposed System

The design comprises of an enclosed box inside which a webcam would be fitted. There will be a hollow through which a person can insert his palm and flash his card. This is used to uniquely identify a person. The other end of the box will be connected to a system which consists of required algorithm which intern is connected to earphones. After flashing the card, through earphone he would be asked for his password. The blind has to enter his password through gestures. The system interprets the gestures and acknowledges accordingly through headphone.

\subsection{Algorithm of ATM accessing for blind}

In this section we have explained the process flow and its implementation as shown in Fig 3.

\subsection{Conversion of RGB Image}

The captured RGB image must be converted to $\mathrm{YCbCr}$ model and obtain the image of $\mathrm{Y}$ plane only as background and foreground can be clearly distinguished as shown in Fig 4 . The following formula can be used for conversion. [6][9]

$$
\begin{aligned}
& \mathrm{Y}=0.299 * \mathrm{R}+0.587 * \mathrm{G}+0.114 * \mathrm{~B}[5][10] \\
& \mathrm{Cb}=-0.168736 * \mathrm{R}-0.331264 * \mathrm{G}+0.5 * \mathrm{~B}[8] \\
& \mathrm{Cr}=0.5 * \mathrm{R}-0.418688 * \mathrm{G}-0.081312 * \mathrm{~B}
\end{aligned}
$$

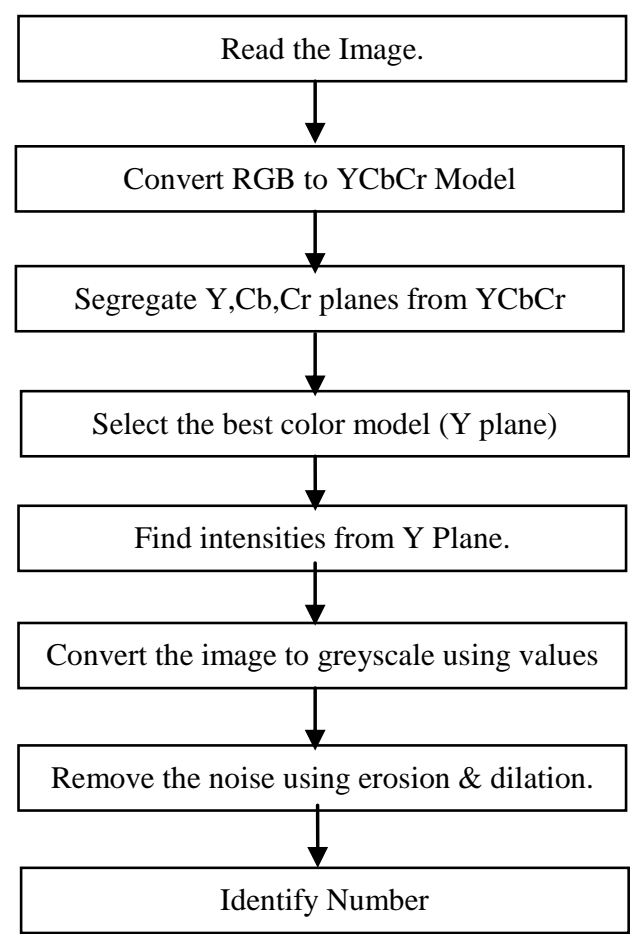

Fig 3: Algorithm flow
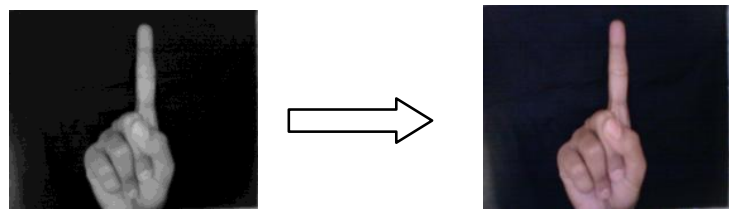

Fig 4 : RGB to Y plane

\subsection{Identification of Hand}

The hand gesture should be separated from background as our focus is only on hand part of the captured image. This is accomplished by separating out background and hand gesture at different gray levels as shown in Fig 5. This process is called segmentation.
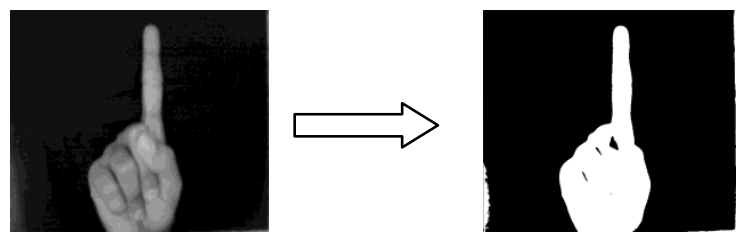

Fig 5: Segmentation

\subsection{Morphological Operations}

Morphology is set of image processing operations that process images based on shapes. The morphological operations apply structuring element to an input image creating an output image of same size. The basic morphological operations are dilation/erosion. They are used to remove noise present in the image. Erosion is used to remove noise present in the background while dilation removes noise present in the hand ie exactly opposite of erosion[5]. 

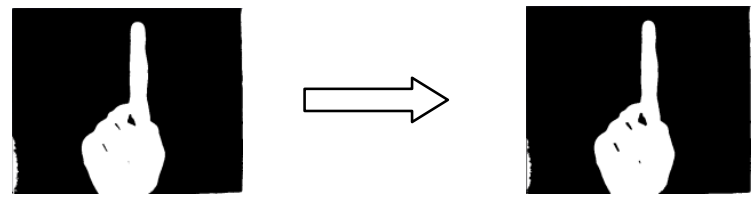

Fig 6: Erosion
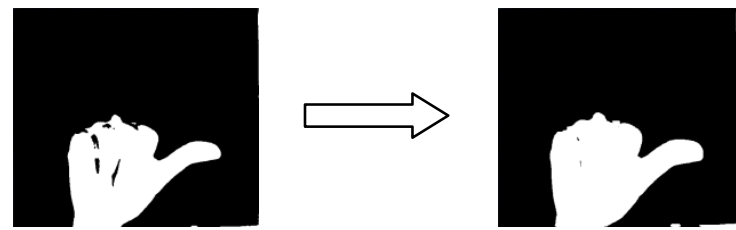

Fig 7: Dilation

\subsection{Identification of Gestures}

Counting is done to determine how many fingers are opened and which of them are open based upon this test results the actual count is obtained.

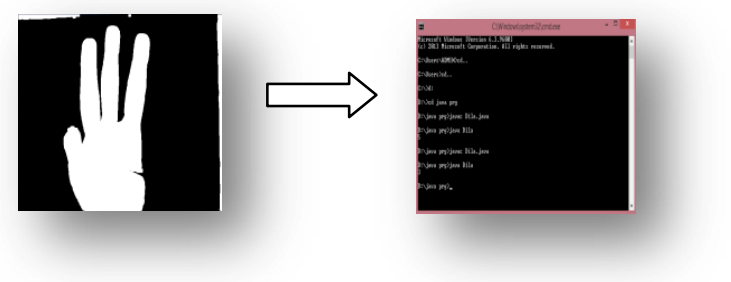

Fig 8: Gesture is identified as number 3

\section{RESULTS}

The gestures are captured continuously as a video and are mapped to identify the numbers. When the correct 4 digit sequence of numbers comprising the password is obtained the user can carry out further transactions else he would have 3 chances to reshow his password failing which the user is identified as a robber.

\subsubsection{Advantages and Disadvantages}

In this section we discuss about advantages and disadvantages of this setup and implementation.

The major advantages are firstly Blind people need not depend on anyone for his/her transactions. It provides higher security. Even a person who does not know Braille or an illiterate person can easily do his/her transactions. It is Safe and error-free authentication through enclosed box. And most importantly it's cost effective.

The few disadvantages are that the Gestures should be shown properly. And Indian sign language should be known.

\section{APPLICATIONS}

- This system can be used for house security purpose.

- The proposed system provides authentication hence can be used in bank safe lockers.

- It can be used in police station to prevent high profile prisoners from escaping.

\section{FUTURE SCOPE}

Different mechanisms can be used to authenticate the user into the system before showing the password

\section{CONCLUSION}

The ATM processing system is developed to demonstrate the possibility of simple hand gesture based input which provides secure transactions. The efficiency of the system is based on how well the system interprets the change in hand gestures. Our proposed system is helpful not only for blind but even illiterate people can use the system and blind need not learn Braille as well. All that they need to know is the Indian sign language of numbers.

\section{REFERENCES}

[1] Blindness and Visual Impairment: Global Facts. http://www.iapb.org/vision-2020/global-facts.

[2] Audio ATM's Then and Now at the wayback Machine, ATM Marketplace.com 2002.

[3] Huddar, S.R.; Rupanagudi, S.R.; Kalpana, M.; Mohan, S., "Novel high speed vedic mathematics multiplier using compressors," Automation, Computing, Communication, Control and Compressed Sensing (iMac4s), 2013 International Multi-Conference on , vol., no., pp.465,469, 22-23 March 2013

[4] Akshay Dekate, Anam Kamal, Surekha K.S.-E\&TC, AlT, Pune "MAGIC GLOVE- WIRELESS HAND GESTURE HARDWARE CONTROLLER" IEEE Electronics and Communication systems(ICECS)

[5] Ravoor, P.C.; Rupanagudi, S.R.; Ranjani, B.S., "Detection of multiple points of contact on an imaging touch-screen," Communication, Information \& Computing Technology (ICCICT), 2012 International Conference on , vol., no., pp.1,6, 19-20 Oct. 2012

[6] YUV, YCbCr, YPbPr color spaceshttps://discoverybis.net/support.

[7] Umbaugh Scot E, Computer vision and Image Processing, Prentice Hall, NJ,1998, ISBN 0-13-264599-8

[8] Rupanagudi, S.R.; Ranjani, B.S.; Nagaraj, P.; Bhat, V.G.; Thippeswamy, G., "A novel cloud computing based smart farming system for early detection of borer insects in tomatoes," Communication, Information \& Computing Technology (ICCICT), 2015 International Conference on , vol., no., pp.1,6, 15-17 Jan. 2015

[9] Rupanagudi, S.R.; Jabeen, F.; Savarni K R, V.R.; Adinarayana, S.; Bharadwaj, V.K.; Karishma, R.; Bhat, V.G., "A novel video processing based cost effective smart trolley system for supermarkets using FPGA," Communication, Information \& Computing Technology (ICCICT), 2015 International Conference on , vol., no., pp.1,6, 15-17 Jan. 2015

[10] Ravoor, P.C.; Ranjani, B.S.; Rupanagudi, S.R., "Optimized fingertip blob recognition for image processing based touch-screens," Recent Advances in Computing and Software Systems (RACSS), 2012 International Conference on, vol., no., pp.104,108, 2527 April 2012 